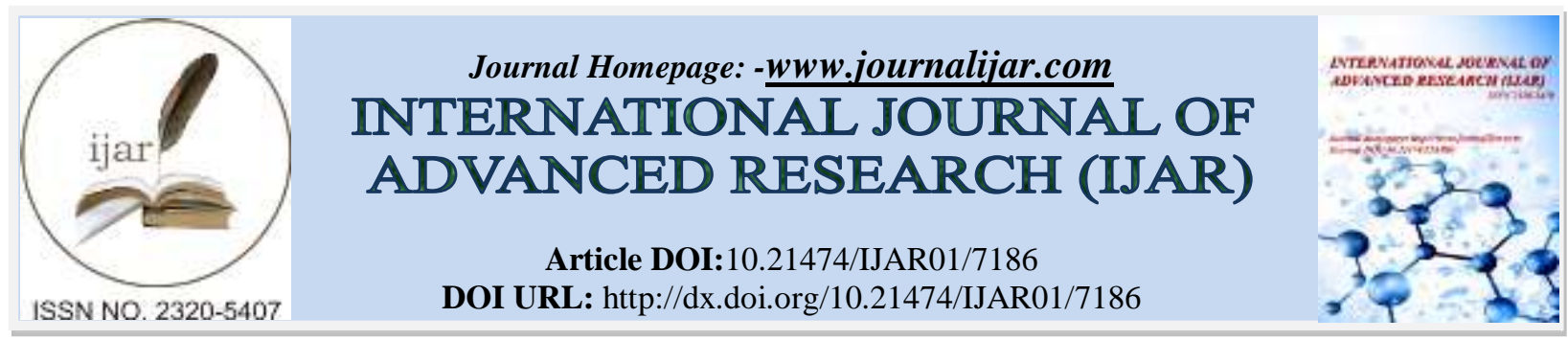

RESEARCH ARTICLE

\title{
FACTORS CONTRIBUTING TO DEPENDENCE ON ILLICIT ALCOHOL AMONG RESIDENTS AGED (15-50) YEARS IN SHITOCHI SUB-LOCATION, KENYA: A DESCRIPTIVE CROSS-SECTIONAL STUDY.
}

\section{Lihavi musindi marjorie ${ }^{1}$ and Phelix mulunda nasiombe ${ }^{2}$.}

1. Association of Public Health Officers Kenya.

2. Kenya Oral Literature Association.

Manuscript Info
Manuscript History
Received: 02 April 2018
Final Accepted: 04 May 2018
Published: June 2018
Keywords:-
Illicit alcohol, dependence, frequency of
utilization.

Illicit alcohol, dependence, frequency of .

\begin{abstract}
The harmful use of alcohol is a component cause of more than 200 disease and injury conditions in individuals, most notably alcohol dependence, liver cirrhosis and injuries in the world. The present study aimed to determine the factors which contribute to the dependence on illicit alcohol among the residents of Shitochi sub-location in Kenya. It further intended to establish the association between socio-economic, cultural and psychological factors on dependence of illicit alcohol consumption in the region. A total of 385 participants between the ages of 15-50 were sampled through a stratified random sampling technique and data was collected through questionnaires. Multinomial logistic regression was used as the statistical model in this study. Of all 385 participants, 341(89\%) were men and majority were above 40 years of age.61 (17\%) participants admitted that they had increased their alcohol intake in the past year and $146(43 \%)$ stated that their frequency of utilization had decreased.219 (57\%) of the participants had no intention of quitting to drink illicit brew. There was a strong association $(\mathrm{P}=$ 0.011 ) between affordability, availability and accessibility and dependence of illicit alcohol in the region. Occupation also had a strong association $(\mathrm{P}=0.027)$ with the dependence of illicit alcohol in the region. Most socio-economic factors were clearly linked to the dependence on illicit brew in the region. It is therefore important for the government to educate the people on the negative impacts of illicit alcohol to their health and general well-being and emphasize that abstinence is the best way to control dependency of illicit brew.
\end{abstract}

Copy Right, IJAR, 2018,. All rights reserved.

\section{Background:-}

The World Health organization defines unrecorded/illicit alcohol consumption as "alcohol consumption which is not reflected in official statistics on alcohol consumption".

The harmful use of alcohol is a component cause of more than 200 disease and injury conditions in individuals, most notably alcohol dependence, liver cirrhosis and injuries. Worldwide consumption of alcohol in 2010 was equal to 6.2 liters pure alcohol consumed per person aged 15 years or older, which translates to 13.5 grams of pure alcohol per day. A quarter of this consumption $(24.8 \%)$ was unrecorded i.e. homemade alcohol illegally produced or sold 
outside normal government controls. In 2012,139 million DALYs (disability-adjusted life years) or 5.1\% of global burden of disease were attributed to alcohol consumption (WHO, 2014).

During November 24-27, 2012, the Arizona Department of Health Services (ADHS) was notified that eight male inmates of prison A, a maximum security prison, had been hospitalized for treatment of an acute neurologic condition suspected to be botulism. All eight patients reported drinking pruno, an illicitly brewed alcoholic beverage that has been associated with botulism outbreaks in prisons. (CDC, 2012).

By late adolescence, $78.2 \%$ of US adolescents had consumed alcohol, $47.1 \%$ had reached regular drinking levels defined by at least 12 drinks within a given year, and $15.1 \%$ met criteria for lifetime abuse. The opportunity to use illicit drugs was reported by $81.4 \%$ of the oldest adolescents, drug use by $42.5 \%$, and drug abuse by $16.4 \%$. The median age at onset was 14 years for alcohol abuse with or without dependence, 14 years for drug abuse with dependence, and 15 years for drug abuse without dependence (Joel et al, 2012).

In December 2011, media outlets around the globe reported the shocking news that over 150 people had died in West Bengal, India, from toxic alcohol poisoning. According to most accounts, these deaths were related to the consumption of illegally produced alcohol. Tragedies like this one raise awareness in the public health community about the production and consumption of beverages that do not undergo quality controls. There are two major drivers of the informal beverage alcohol market which include culture and price (Guillermo Cantor, 2018).

A study conducted by ICAP indicated that majority of alcoholic drinks produced and traded around the world today are from domestic manufacturers whether legal or illegal. The top ten multinational producers of beer, wine and spirits accounts for a surprisingly small fraction of the alcohol produced worldwide. In some areas, especially in low and middle income economies, it may account for more than half of the total alcohol consumed but varies widely from community to community (Simpson and Botha, 2009).

There are a number of pathways related to alcohol quality that may lead to acute or chronic health problems. The following constituents and contaminants of alcoholic beverages were identified as likely contributors to these problems: toxic metals (e.g. lead) from contaminated water sources or unsuitable distillation equipment; volatile constituents, such as acetaldehyde or higher alcohols, which may be produced in significant amounts due to faults in production technology or microbiological spoilage; ethyl carbamate (urethane), a carcinogenic contaminant with major occurrence in certain fruit and sugarcane spirits; biologically active flavour compounds (e.g. coumarin in cosmetics used as non-beverage alcohol); toxic compounds used to denature alcohol (e.g. methanol or diethyl phthalate). In addition, the often higher ethanol content may have detrimental health effects (Jurgem Et al, 2010)

In Rwanda, the sale of the liquors is a lucrative business which generates a lot of revenue for people dealing in it. A lot of people, who do not understand the health risks of consuming the liquors, keep taking them and that brings a lot of money to the sellers. In addition, the production of such brews is cheap and takes less time to produce. Residents say a 72cl bottle of the banned liquors goes for less than Rwf200 which is far cheaper than the traditional and wellpackaged banana beer, which goes for Rwf300 for a bottle of about 33cl (Pierre, 2013).

Mothers of one of the poorest areas in South Africa are drinking to deliberately damage their unborn babies just so that they can claim disability benefit. Life is so tough with unemployment high and crime rampant in South Africa's Eastern Cape that a newborn baby represents a form of income for the mothers. (Crawford, 2013).

An increase in current, binge drinking and hazardous or harmful drinking prevalence was observed from 2005 to 2008 in South Africa. For populations with high rates of hazardous alcohol use, both population-wide measures and individual-based interventions have been shown to have a notable impact on reducing the global burden of alcohol misuse. Most alcohol-related harm is attributable to hazardous/harmful drinkers who make disproportionate use of primary health care systems, but often go undetected and untreated for long periods, even though brief, easily delivered interventions are effective in this group of people (K Peltzer Et al, 2011).

About $85 \%$ of alcohol consumption is illicit in Kenya. The drinking feeds social problems, such as violence and poverty, and worse. Deaths and blindness from chang'aa contaminated with methanol or other chemicals are common in Kenya, with dozens, sometimes hundreds, of drinkers dying within a few days (Dixon, 2010). The 
consumption of chang'aa tops at 76.7 per cent, wines and spirits 39.5 per cent, bhang 22.9 per cent, heroine 6.1 per cent and cocaine 4.8 percent (NACADA, 2012)

In Shitochi sub-location, illicit alcohol has led to the increased number of school dropouts. This highly affects the level of productivity because there is a higher population of dependent individuals in the region. Family instabilities are also high and husbands fail to fulfill the conjugal rights of their wives. Furthermore, domestic violence is also high in the sub-location and this has been linked to high rates of consumption of illicit brew which contributes to family breakups. The victims also do not have stable jobs to take care of their families but instead strain the financial recourses of the family later in the purchase of illicit brew hence leading to high poverty rates. Individuals have also gone blind and even died due the consumption of poisoned brew. There are women who also drink the illicit brew even when pregnant and these leads to children being born with fetal alcohol syndrome or in most cases both mother and child die due to over bleeding during delivery.

No study has assessed this issue among the people of Shitochi sub-location. The present study aimed to examine the factors that contribute to the dependence of illicit brew among the residents of Shitochi sub-location in Kenya due to its high negative effects to the population.

\section{Objectives:-}

The present study intended to identify the factors that contribute to the dependence on illicit alcohol among the residents of Shitochi sub-location, Kenya.

\section{Methods:-}

\section{Design and Setting:-}

Participants of the study were individuals who drunk the illicit alcohol aged between 15-50 years since they are the group that abuses illicit alcohol in the region more than the rest as stated by the chief of the area. The study employed a quantitative, cross-sectional study design since the observations were made at a point in time and descriptive data collected by use of structured questionnaires.

\section{Sampling:-}

Since this population was more than 10000, the sample size was calculated using the first part of the Fisher's (1978) formulae for sample size determination as shown below;

$\mathrm{N}=\mathrm{Z}^{2}(\mathrm{p})(\mathrm{q}) \div \mathrm{d}^{2}$ Calculated as:

Calculated as: $n=\frac{1.96^{2} \times 0.5 \times 0.5}{0.05^{2}}=384.16$

Therefore the sample size that was used in the present study was 385 residents. Participants were selected using stratified random sampling technique and all participants who did not consent to participate were all excluded.

\section{Research Instrument:-}

A pilot study was conducted at Khalaba village where the questionnaire was pretested. Thirty nine (39) residents between the ages of 15-50 who were willing to participate were involved in the pilot study. The main objective of the pilot study was to evaluate the feasibility, time, cost adverse events and reliability and validity of the data collection tool. This enabled the improvement upon the study design and data collection tools prior to performance of the full scale research project. The pretest also assessed whether the questions were clear and could be understood by the participants.

\section{Data collection technique:-}

A self-administered questionnaire with close ended questions was issued to all subjects with the subjects being allowed to exercise an informed consent before responding to questions in the questionnaire. Observations were also made during the study. Each questionnaire was filled within 10 and 15 minutes.

\section{Ethical Aspects:-}

Through the department chair of Public Health, a proposal was presented before UEAB Institutional Review Ethics Committee (IREC) which granted ethical approval and permission for this study to proceed. This was done to 


\begin{tabular}{|c|c|c|c|}
\hline Variable & Men/N 341(\%) & Women/N 44(\%) & Total $385(\%)$ \\
\hline $\begin{array}{l}\text { Age } \\
\text { Below } 20 \text { years } \\
21-30 \text { years } \\
31-40 \text { years } \\
41-50 \text { years } \\
\end{array}$ & $\begin{array}{l}14(4.1) \\
68(20) \\
126(40) \\
133(49)\end{array}$ & $\begin{array}{l}0(0) \\
27(61.4) \\
9(20.5) \\
8(18.2)\end{array}$ & $\begin{array}{l}14(3.3) \\
95(24.7) \\
125(35.3) \\
141(36.7)\end{array}$ \\
\hline $\begin{array}{l}\text { Marital status } \\
\text { Single } \\
\text { Married } \\
\text { Separated } \\
\text { Divorced } \\
\text { Widowed }\end{array}$ & $\begin{array}{l}59(17.3) \\
244(71.5) \\
20(50.9) \\
10(2.9) \\
8(2.3)\end{array}$ & $\begin{array}{l}18(40.9) \\
26(59.1) \\
0(0) \\
0(0) \\
0(0)\end{array}$ & $\begin{array}{l}77(20) \\
270(70) \\
20(53) \\
10(2.7) \\
8(2.0)\end{array}$ \\
\hline $\begin{array}{l}\text { Frequency of utilization } \\
\text { Increased } \\
\text { About the same } \\
\text { Decreased }\end{array}$ & $\begin{array}{l}61(17.9) \\
134(39.3) \\
146(42.8)\end{array}$ & $\begin{array}{l}4(9) \\
20(45.5) \\
20(45.5)\end{array}$ & $\begin{array}{l}65(17) \\
154(40) \\
166(43)\end{array}$ \\
\hline $\begin{array}{l}\text { Education } \\
\text { Primary } \\
\text { Secondary } \\
\text { Diploma/certificate } \\
\text { University level }\end{array}$ & $\begin{array}{l}131(38.4) \\
120(35.2) \\
54(15.8) \\
36(10.6)\end{array}$ & $\begin{array}{l}19(43.2) \\
19(43.2) \\
4(9.1) \\
2(4.5)\end{array}$ & $\begin{array}{l}150(39) \\
139(36) \\
58(15) \\
38(10)\end{array}$ \\
\hline $\begin{array}{l}\text { Occupation } \\
\text { Unemployed } \\
\text { Self-employed } \\
\text { Employed (private) } \\
\text { Employed (government) }\end{array}$ & $\begin{array}{l}79(23.2) \\
189(55.4) \\
33(9.7) \\
40(11.7)\end{array}$ & $\begin{array}{l}17(38.6) \\
15(34.1) \\
2(4.5) \\
10(22.7)\end{array}$ & $\begin{array}{l}96(25) \\
204(53) \\
35(9) \\
50(130\end{array}$ \\
\hline $\begin{array}{l}\text { Monthly income } \\
\text { Less than } 3,000 \\
3,001-5,000 \\
5,001-7,500 \\
7,501-10,000 \\
\text { More than } 10,000\end{array}$ & $\begin{array}{l}144(42.2) \\
46(13.5) \\
23(6.7) \\
33(9.7) \\
95(27.9)\end{array}$ & $\begin{array}{l}22(50) \\
7(15.9) \\
4(9.1) \\
2(4.5) \\
9(20.5)\end{array}$ & $\begin{array}{l}166(43) \\
53(14) \\
27(7) \\
35(9) \\
104(27) \\
\end{array}$ \\
\hline $\begin{array}{l}\text { Reason for use } \\
\text { Availability } \\
\text { Affordability } \\
\text { Accessibility } \\
\end{array}$ & $\begin{array}{l}85(24.9) \\
203(59.5) \\
53(15.5)\end{array}$ & $\begin{array}{l}11(25) \\
24(54.5) \\
9(2.6)\end{array}$ & $\begin{array}{l}96(25) \\
227(59) \\
62(16)\end{array}$ \\
\hline $\begin{array}{l}\text { Helps in interaction } \\
\text { Yes } \\
\text { No }\end{array}$ & $\begin{array}{l}282(82.7) \\
59917.30\end{array}$ & $\begin{array}{l}34(77.3) \\
10(22.7)\end{array}$ & $\begin{array}{l}316(82) \\
69(18)\end{array}$ \\
\hline $\begin{array}{l}\text { It causes addiction } \\
\text { Yes } \\
\text { No }\end{array}$ & $\begin{array}{l}264(77.4) \\
77(22.6)\end{array}$ & $\begin{array}{l}40(90.9) \\
4(9.1)\end{array}$ & $\begin{array}{l}304(79) \\
81(21)\end{array}$ \\
\hline $\begin{array}{l}\text { Helps in stress } \\
\text { Yes } \\
\text { No }\end{array}$ & $\begin{array}{l}208(61) \\
133(39)\end{array}$ & $\begin{array}{l}35(79.5) \\
9(20.5) \\
\end{array}$ & $\begin{array}{l}243(63) \\
142(37) \\
\end{array}$ \\
\hline $\begin{array}{l}\text { Intention of quitting } \\
\text { Yes } \\
\text { No }\end{array}$ & $\begin{array}{l}146(42.8) \\
195(57.2)\end{array}$ & $\begin{array}{l}20(45.5) \\
24(54.5)\end{array}$ & $\begin{array}{l}166(43) \\
219(57)\end{array}$ \\
\hline $\begin{array}{l}\text { Busaa is a traditional } \\
\text { drink } \\
\text { Yes } \\
\text { No }\end{array}$ & $\begin{array}{l}338(99.1) \\
3(0.9)\end{array}$ & $\begin{array}{l}43(97.7) \\
1(0.3)\end{array}$ & $\begin{array}{l}381(99) \\
4(1)\end{array}$ \\
\hline $\begin{array}{l}\text { Chang'aa is a traditional } \\
\text { drink }\end{array}$ & & & \\
\hline
\end{tabular}




\begin{tabular}{|l|l|l|l|}
\hline Yes & $200(58.7)$ & $19(43.2)$ & $354(92)$ \\
No & $14(41.3)$ & $25(56.8)$ & $31(8)$ \\
\hline
\end{tabular}

protect and handle any legal matters that may arise during the study and no harm was done to the subjects. Every participant was allowed to make an informed consent before being involved in the study.

Table No 1:-Title: Demographic characteristics of participants, socio economic, psychological and cultural factors associated with the dependence on illicit alcohol in Shitochi sub-location.

Confidentiality was also highly maintained throughout the process. All personal information obtained from the participants in the study was never revealed in reports and publications. To ensure this, codes were used on questionnaires and participants were not required to reveal their identity.

\section{Statistical Analyses:-}

The collected data were coded and analyzed using statistical package for social sciences (SPSS) 20 version. Multinomial regression was used to find possible associations between the variables and a $\mathrm{P}$ value of less than 0.05 was considered as a significant level. Frequencies and percentages were also used.

\section{Results:-}

The table 1 shows the demographic characteristics of the participant and the socio economic, psychological and cultural factors associated with the dependence of illicit alcohol in Shitochi sub-location. Majority were males at $89 \%$ and females at $11 \%$. Respondents between $41-50$ years were the most at $37 \% .70 \%$ of the participants were married .In the present study, affordability was the main reason as to why most participants drunk illicit alcohol in the region at 59\%.Most participants went to school up to primary level (39\%) and are also self-employed(53\%) with the highest getting an income of less than 3000 shillings(43\%). $79 \%$ of the participants agreed that illicit brew was addictive and most of them had no intention of quitting the drink. Most of them also claimed that illicit alcohol helps them cope with stress. The participants also acknowledged to the fact that busaa is a traditional drink and it is the one that is used in large quantities during ceremonies unlike chang'aa whereby only $57 \%$ identified it as a traditional drink.

Table No 2:- Title: Hypotheses Coefficients ${ }^{\mathrm{a}}$

\begin{tabular}{|c|c|c|c|c|c|c|}
\hline \multirow{2}{*}{\multicolumn{2}{|c|}{ Model }} & \multicolumn{2}{|c|}{ Unstandardized Coefficients } & \multirow{2}{*}{$\begin{array}{l}\text { Standardized } \\
\text { Coefficients } \\
\text { Beta }\end{array}$} & \multirow[t]{2}{*}{$\mathrm{T}$} & \multirow[t]{2}{*}{ Sig. } \\
\hline & & $\mathrm{B}$ & Std. Error & & & \\
\hline & (Constant) & 1.596 & .366 & & 4.362 & .000 \\
\hline & what is your occupation & -.208 & .093 & -.259 & -2.241 & .027 \\
\hline & $\begin{array}{l}\text { what is your level of } \\
\text { education }\end{array}$ & .132 & .080 & .174 & 1.647 & .102 \\
\hline & $\begin{array}{l}\text { what is your monthly } \\
\text { income }\end{array}$ & -.009 & .049 & -.021 & -.180 & .858 \\
\hline & $\begin{array}{l}\text { what made you start } \\
\text { using it }\end{array}$ & .247 & .095 & .215 & 2.589 & .011 \\
\hline & Unemployment & .168 & .163 & .102 & 1.031 & .304 \\
\hline & Poverty & -.086 & .135 & -.058 & -.639 & .524 \\
\hline & helps me interact & .193 & .161 & .101 & 1.200 & .232 \\
\hline
\end{tabular}

a. Dependent Variable: frequency of utilization

Affordability, availability, accessibility and occupation predict the dependence on illicit alcohol in the region with Pvalues less than 0.05 .

\begin{tabular}{|c|c|c|c|c|c|c|}
\hline \multicolumn{7}{|c|}{ Coefficients $^{\mathrm{a}}$} \\
\hline \multirow{2}{*}{\multicolumn{2}{|c|}{ Model }} & \multicolumn{2}{|c|}{ Unstandardized Coefficients } & \multirow{2}{*}{$\begin{array}{l}\text { Standardized } \\
\text { Coefficients } \\
\text { Beta }\end{array}$} & \multirow[t]{2}{*}{$\mathrm{T}$} & \multirow[t]{2}{*}{ Sig. } \\
\hline & & $\mathrm{B}$ & Std. Error & & & \\
\hline \multirow[t]{3}{*}{1} & (Constant) & 2.891 & .321 & & 8.993 & .000 \\
\hline & helps me cope with stress & -.027 & .120 & -.018 & -.221 & .825 \\
\hline & $\begin{array}{l}\text { does illicit brew cause } \\
\text { addiction }\end{array}$ & .178 & .140 & .098 & 1.266 & .208 \\
\hline
\end{tabular}




\section{intention of quitting}

$-.520$

.117

$-.352$

$-4.436$

.000

a. Dependent Variable: frequency of utilization

The intention of quitting predicts the dependence on illicit alcohol in Shitochi sub-location since it had a P-value of less than 0.05 .

\section{Discussion:-}

In Shitochi sub-location, most of the participants were males at $88.7 \%$ compared to females at $11.3 \%$ because women were not willing to participate in the study and also women rarely go to the illicit brew dens but drink it at the comfort of their homes. The fact that traditions do not support women drinking could also be the reason as to why they were embarrassed to admit that they drink and thus participate in the study. In addition, the women are the ones who make the illicit brew and sell it to the residents. Most of these women are widowed and explained that they sell the brew to take care of their children.

Under normal circumstances, the males are expected to provide for their families and the fact that most males were found in the dens is an indication that the level of productivity in the region is low because these men waste a lot of time in the dens.

$60 \%$ of the participants were youths. The married group of people were the most among the participants at $70 \%$ compared to the singles, the separated, the widowed and the divorced.

In the past one year, $43 \%$ of the participants stated that their frequency of drinking illicit brew had reduced and $40 \%$ of the participants said that their levels of dependency have not changed. Only $17 \%$ of the participants admitted that their level of dependency had increased. Most of the participants said that their drinking frequency had decreased because of the increasing economic demand. This is ironical because under positive circumstances they could have said that their frequency of drinking had decreased because they saw that illicit brew affects their lives negatively. This shows that the frequency of drinking is determined by how much money one has in that the more he has the more he will abuse illicit brew and the less money one has the less frequent the drinking of illicit brew.

Among the participants, 53\% were jua kali industry self-employed. They explained they are self-employed because of lack of employment opportunities. The unemployed participants were $26 \%$ of the participants which is also a high percentage and it thus shows how high the dependent population is in the sub-location and the fact that the level of productivity in the region is low.

Most participants only reached primary school. The number of participants reduces as the hierarchy of education increases to university level at only $10 \%$. Over $90 \%$ of the participants who said they reached primary school are class 5 and class six dropouts. This is alarming due to the fact that there is free primary education and adult education has been introduced by the government yet most participants did not finish primary school. Over $70 \%$ of the participants who reached in secondary school actually dropped out in form two and form three. The results also indicate that most people do not reach tertiary institutions in a time when the government is making efforts to increase the number of tertiary institutions even in rural areas. With a high percentage of illiterate individuals, it means that their understanding on the negative effects of illicit brew is very low and this will be a major challenge during health campaigns.

$43 \%$ of the participants earn below Ksh 3000. Most of the participants in this category also work in the jua kali industry and the ones who earn more than Ksh10000 have reached tertiary education and also work in gold mines. This indicates that the people who drink illicit brew mainly belong to the lower social status of the society and not the ones who earn more money.

Most participants started using illicit brew because of its affordability while others used it because of its availability and accessibility. Illicit brew was as cheap as $10 \mathrm{KSH}$ compared to beer which one needs a lot of money (e.g. Ksh 200 Tusker brand). In addition to affordability illicit brew is also effective since it has a very high alcoholic content and thus the participants did not need to buy a lot of alcohol and stated that they are able to save for food and other personal needs. The fact that most of the participants' monthly income is less than Ksh 3000 also proves that the people of Shitochi sub-location drink illicit brew because of its affordability. 
63\% of the participants agreed that by drinking illicit brew they are relieved from the stress/depression in that they are able to escape from reality and not worry about their problems. In real sense, no alcohol or drug can relieve one from a stressful situation. The alcohol just does that temporarily, and when one is sober his problems have not gone away. Addiction is a major psychological factor that brings about dependency, over $75 \%$ of the participants agreed that drinking of illicit brew causes addiction and thus addiction brings about the dependency of illicit brew in the region. They admitted that since they are addicts, they cannot move on with their daily activities without drinking illicit brew. This explains why over $50 \%$ of the participants had no will to quit drinking illicit brew.

The fact that $99 \%$ of the participants agreed that busaa is a traditional drink is also an indication that cultural factors can lead to dependency on illicit brew in Shitochi sub-location. The participants also said that no traditional ceremony is done without the presence of busaa and during these ceremonies, licenses are given by the authorities to allow the brewing and drinking of busaa. Busaa is also the drink that is used in large quantities during traditional ceremonies especially commemoration, bull fighting, child naming ceremonies and traditional weddings.

On the other hand, there is uncertainty on whether chang'aa is a traditional drink or not since over $40 \%$ of the participants disagreed that it is. This is because chang'aa was introduced into the Luhya community in the early 1940's by the Suba from Sudan and also it is not a must for it to be used during traditional ceremonies and if used it is used in small quantities and through the 'back door'.

Some socio-economic factors like occupation, availability, affordability and accessibility predict the dependence on illicit brew in shitochi sub-location with $P$ values below 0.05 with 0.027 on occupation and a strong association of 0.011 on availability, affordability and accessibility of the illicit brew in the region.

Occupation has a negative association with dependence on illicit brew at -.208 in that when one is employed the level of illicit brew dependency is low and the dependency increases as the hierarchy of occupation decreases to unemployment.

The intention of quitting though predicted the dependence of illicit brew in Shitochi sub-location because it has a $\mathrm{P}$ value of .000018 which is a very strong association. The relationship between the intention of quitting and frequency of utilization is a strong negative relationship of -0.520 which means that as an individual's frequency of drinking decreases he/she is has an intention of quitting illicit brew but as the frequency of drinking of an individual increases he/she has no will to quit drinking illicit brew.

\section{Conclusion:-}

The dependence on illicit brew in a particular locale is due to specific factors within the community. These factors could be socio-economic, psychological or cultural factors. Illicit brew production and consumption has brought about many negative effects to the society at large and thus there is a necessity that the factors be eliminated in order to mitigate its dependence among the people.

According to the findings of the present study, the socio-economic factors like occupation, availability, accessibility and affordability played a major role in the dependence on illicit brew compared to psychological and cultural factors. It is therefore important for the government to educate the people on the negative impacts of illicit alcohol to their health and general well-being by emphasizing that abstinence is the best way to control dependency of illicit brew. The government should also help those addicted to quit drinking through rehabilitation and monitoring. Furthermore, the fact that most of the participants had no intention of quitting to drink the illicit brew, policies should be put in place by the government in order to monitor the production and sale of alcohol in Kenya. The church should also be involved because it has a great influence to the behavior and perceptions of people.

\section{Acknowledgements:-}

My sincere gratitude goes to the teaching staff of The University of Eastern Africa Baraton from the school of health sciences, public health department for their relentless and time dedicated to me in order to see me through this research. I would also like to thank Dr. Catherine Gichunge, my parents and friends for their encouragement and support throughout the research period. 


\section{References:-}

1. Alex Crawford, 2013. Women Drinking to Harm Babies. Sky News January $8^{\text {th }} 2013$.

2. CDC. (2012). Botulism from drinking prison-made illicit alcohol-Utah. MMWR. 61:782-4.

3. Dr. Ronald Simpson and Adrian Botha, 2009. .Illicit and Non-Commercial Alcohol-What Can We Do? International Centre for Alcohol Policies (ICAP).

4. Guillermo Cantor, 2018.Understanding Illicit Alcohol. Brown-Forman Corporation.

5. Jean Pierre Bucyensenge, 2013. Why Illicit Trade is flourishing. Kigali.

6. Jerry Okungu, May 23, 2010. Why is Illicit Brew Killing So Many Kenyans and Ugandans? Nairobi, Kenya

7. Joel Swendsen, PhD; Marcy Burstein, PhD; Brady Case, MD; et al,2012,Use and Abuse of Alcohol and Illicit Drugs in US Adolescents Results of the National Comorbidity Survey-Adolescent Supplement. Arch Gen Psychiatry

8. Jürgen Rehm ,Fotis Kanteres ,Dirk W. Lachenmeier, 2010. Unrecorded consumption, quality of alcohol and health consequences. Drug and alcohol review by APSAD https://doi.org/10.1111/j.1465-3362.2009.00140.

9. K Peltzer, A Davids, P Njuho,2011 .Alcohol use and problem drinking in South Africa: findings from a national population-based survey. Afr J Psychiatry 14:30-37

10. NACADA, 2012. Western Province Leaders Blamed for Frustrating Efforts to Curb Drug Abuse among the Youth. Article.

11. Robyn Dixon, 2010. For Many in Kenya, Illegal Brew has a Sting; Deaths and Blindness from Chang'aa Contaminated with Methanol. Los Angeles Times $31^{\text {st }}$ August.

12. WHO, 2014. Global status report on alcohol and health. World Health Organization. 